\title{
Aprendices de economistas
}

\author{
CRISTINA RIVERA \\ Departamento de Economía \\ UCA, San Salvador
}

RESUMEN: La autora hace un recorrido por la labor intelectual del economista jesuita Francisco Javier Ibisate, fundador de esta revista, a través de su faceta de docente. Ibisate formó a generaciones de economistas en el país. El artículo ayuda a entender por qué sus ideas y actitudes fueron

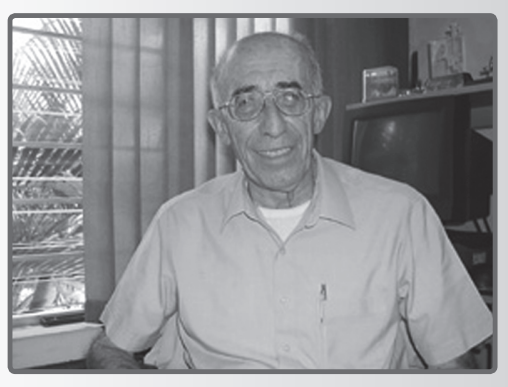
tan importantes para ellos.

ABSTRACT: The author makes an outlook over the intellectual labor of the Jesuit economist Francisco Javier Ibisate, founder of this magazine, through his educative work. Ibisate formed generations of economists in the country. The paper helps to understand why his ideas and attitudes where son important for them. 
$\mathrm{P}$ adre, sé que no hablo sólo por mi persona al expresar que ahora somos economistas huérfanos. Sé que los catedráticos del departamento de economía ahora no tenemos a quien llamar "padre".

Eso representaba usted para nosotros: un padre que nos orienta, nos guía, nos ilumina, nos inspira, nos acoge y protege, nos escucha y aconseja; un maestro en cuyas aulas y clases aprendimos y aprehendimos a amar la ciencia económica, el conocimiento, la investigación y, sobre todo, la verdad.

"Mañana me trasladaré al departamento de Economía, donde me han preparado un buen cubículo. Quiero decir, con toda sinceridad una cosa: la mayoría de profesores del departamento ha sido alumno mío y mi alegría es ver que ahora soy yo quien tengo que aprender de todos ellos, con sus estudios de post grado y su dedicación 'juvenil' a la investigación y la docencia"1.

Talvez de lo que no estaba al tanto el Padre es que muchos de nosotros somos hoy "aprendices de economistas" (como él solía referirse a su persona), porque él tocó y marcó permanentemente nuestras vidas, y quisimos seguir sus pasos y ser aprendices suyos.

La primera vez que vi al Padre Ibis fue en una entrevista televisiva. Recuerdo cuando afirmó que para hablar de inflación había que preguntarle a las amas de casa. El entrevistador le preguntó sobre el rumbo de la economía nacional, yo era muy joven para recordar ahora sus respuestas, pero lo que nunca olvidaré es la sensación que experimenté: desde entonces supe que si necesitaba saber de economía, él era la persona indicada. Años después, entré a la carrera de Economía en la UCA y tuve la dicha y el privilegio de ser su alumna y posteriormente trabajar con él ayudando como instructora y luego compartiendo algunos años laborales en el departamento de Economía.

De sus enseñanzas acerca de los fundamentos de la ciencia económica en sus clases de introducción a la economía recordamos cómo en ellas nos enseñó a reflexionar sobre las revoluciones tecnológicas, las cuales, a la vez que contribuyen a cerrar la brecha entre el crecimiento geométrico de la población (y sus necesidades) y el crecimiento aritmético de los recursos, son un proceso de creación destructiva o destrucción creativa ${ }^{2}$. Recordamos cómo nos introdujo al estudio de la macroeconomía, enseñándonos que la matriz de coeficientes técnicos nos da la "receta culinaria de la tía María" ${ }^{3}$, y que cada rama productiva de la economía representa un eslabón que es interdependiente y se interrelaciona con todos los sectores económicos. En sus clases también aprendimos que la producción está limitada por la demanda, y que "quienes deciden la contratación de los factores de producción son 
los empresarios que buscan en ello sus beneficios normales; ellos prolongarán su demanda 'efectiva' de factores mientras calculen que los ingresos 'esperados' (demanda global) serán mayores que los ingresos 'necesarios' (oferta global) para cubrir costos de producción; en ese punto de cruce se dará la 'demanda efectiva' de factores de producción" ${ }^{\prime 4}$. Fue también en sus clases de Introducción a la Economía I que nos hizo reflexionar acerca del especial carácter de la economía salvadoreña: una economía mixta, porque divide a los que quieren comprar y no pueden, y a los que pueden comprar y no quieren.

No olvidamos su introducción al análisis microeconómico y cómo nos enseñó acerca de la formación de la demanda, la oferta y los precios, así como las aplicaciones de los traslados de las curvas (de oferta y demanda) en los tres tiempos operacionales de la oferta y en la tela de araña que nos ayuda a comprender el ciclo agrícola. Con el Padre Ibis aprendimos además sobre la elasticidad precio de la demanda y la oferta, que trata de medir la sensibilidad o el grado de reacción de las cantidades demandadas $u$ ofrecidas ante las variaciones de los precios, y cómo nos puede ayudar a comprender la adaptación de la oferta y demanda en el corto y largo plazo en el caso del choque petrolero de 1973-1979. Como parte de ese análisis microeconómico, también conocimos en sus aulas que "si las cantidades de algunos factores son fijas, el producto marginal de un factor variable disminuirá después de traspasar un determinado nivel, conforme aumente la cantidad de ese factor ${ }^{\prime \prime}$ (Ley de los rendimientos no proporcionales). Además, conocimos acerca de la estructura del mercado empresarial: competencia perfecta e imperfecta, analizando los casos de monopolios, polipolios diferenciados y oligopolios que pueden analizarse en dos fases: una fase competitiva de "guerra de cuchillos"6 (guerras de precios, publicidad e inventarios) que genera una "curva de demanda acodada" ${ }^{\prime \prime}$, y una fase en la que los empresarios han descubierto que "el mayor beneficio es la tranquilidad" ${ }^{\prime \prime}$, $y$, por tanto, hacen convenios que pueden ser implícitos o explícitos.

Sin embargo, más allá de aprender con el Padre Ibis acerca de los fundamentos de la ciencia económica, aprendimos el lado humano de la economía, pues el éxito de un modelo económico no debe medirse a través de los incrementos del PIB, sino que debe medirse por el desarrollo de la plena libertad social, entendida esta como libertad del hambre, las necesidades y del temor a la violencia.

También aprendimos que "la historia camina hacia delante, pero viene de atrás; y el momento presente es una tensión entre el pasado que retiene y el futuro que atrae $^{\prime \prime}$, y que si bien los modelos económicos están hechos para remodelarse, no han sido capaces de dar una respuesta humana a 
los grandes problemas humanos: exclusión, marginación, desigualdad, pobreza, desempleo, estancamiento de los aparatos productivos, degradación ambiental, ruptura de los tejidos sociales, insolidaridad social e inequidad de género, entre otros. Reflexionamos acerca de la globalización neoliberal y cómo "se niega a compararse contra sí misma"10, sin tomar en cuenta que "la autoadulación corrompe [y que] la quiebra y la descomposición de los mal Ilamados 'socialismos reales' del este europeo no ocurrieron por la planificación de las economías (...); lo que los perdió fue su permanente negativa a la autocrítica"11. Así, el Padre afirmaba que "cuando uno contempla el siglo XX desde el nuevo milenio Ilega a una conclusión: el mayor signo de debilidad y el peor enemigo que puede tener cualquier sistema es negarse a hacer su propia autocrítica"12, de modo tal que "la globalización hace difícil la globalización" ${ }^{\prime 13}$, pues existe crítica pero no autocrítica.

\section{Una persona que amaba a la UCA}

El Padre Ibis llegó a la UCA en noviembre de 1966. En 1972, le conceden la nacionalidad salvadoreña "quizás por ser buena persona"14, como lo afirma en el artículo "Los treinta años de la UCA", publicado en la edición noviembre-diciembre de 1995 de la revista ECA. Ese artículo resulta de sumo interesante puesto que ahí encontramos de la voz del Padre Ibis un recorrido histórico desde la fundación de la universidad y podemos constatar el profundo amor que él sentía por la institución y su misión; por ello quiero trasladar textualmente algunos de los párrafos escritos por el Padre en dicho artículo:

"Año 1969 (....) Es inolvidable la alegría de aquel primero de enero cuando con el Padre Gondra colocamos los pupitres en las aulas de los dos laboratorios de planta baja y en los edificios prefabricados ${ }^{\prime 15}$.

"Año de 1970. Este y el siguiente año fue un tiempo de deliberación sobre los objetivos y funciones fundamentales de la UCA. Teníamos reuniones continuas en todos los estamentos de la universidad. Ahí se fueron perfilando esas características que Román Mayorga resumió como universidad comprometida, universidad abierta, universidad con conciencia crítica y constructiva y universidad integrada. Una universidad para el cambio social, que actúa con medios universitarios (no partidistas políticos) y desde una inspiración cristiana"16. "Sin embargo, ser conciencia crítica y constructiva de la realidad nacional tuvo siempre consecuencias financieras desagradables y también humanas (...) Las amenazas creaban inseguridad a todos y todos nos quedamos en la UCA. Todos creímos que merecía la pena arriesgar algo o mucho, personal y familiarmente, por fidelidad a los ideales de la UCA"17.

"Década de los 80: Los alumnos fueron los grandes animadores de la UCA, perseverando en sus estudios, en condiciones tan adversas 
de inseguridad y toques de queda. (...) El lunes siguiente a la ofensiva militar de la guerrilla en la capital, estando copada la universidad por fuerzas gubernamentales, los alumnos se asomaban a las verjas de las entradas para preguntar si había clases. Pusimos unas cartulinas: 'Hoy no hay clase'. Creo que esa fue la única semana que no pudimos dar clases en todo el historial de la UCA. Han sido nuestros alumnos los principales acompañantes de la década conflictiva. Con unos alumnos así no había más remedio que seguir dando clases"18.

"Al terminar la década de los 80 se troncha el proceso de creación destructiva, convertido en destrucción destructiva en la mente de quienes realizaron lo que Marha Doggett titulara la muerte anunciada. Como dijo Monseñor Rivera: 'Los mató el mismo odio que mató a Monseñor Romero'. Por aquí comencé y por aquí quisiera acabar, porque la década de los noventa ya no son memorias, sino hechos presentes. 'La UCA no ha muerto', dijo el padre Tojeira. Y si la UCA no ha muerto, queda algo por añadir"19.

"Sabemos que no fue tarea fácil reemplazar a los seis jesuitas asesinados. Fue un golpe muy duro. Recuerdo que en las navidades de 1989 estábamos algo preocupados por la posible disminución del alumnado a raíz de los sucesos y de los ataques contra la UCA. Preocupación fallida: hubo tantas o más solicitudes de ingreso de nuevos aspirantes y los alumnos antiguos perseveraron con orgullo en su universidad. Incluso circulaba una viñeta: 'Soy 100\% UCA'. Esta viñeta hay que dedicarla también a todos los profesores, jefes de unidad, personal administrativo y demás trabajadores con o sin uniforme. Creo que podemos decir que no hubo deserción, sino orgullo de seguir estando en la UCA"20.

El amor del Padre Ibis por nuestra universidad se hizo sentir en muchos de sus artículos, a pesar de que éstos no trataran expresamente acerca de la universidad, una muestra de ello la encontramos en su artículo "La planificación del desarrollo social y económico"21, donde traslada algunas de sus ideas sobre la necesidad de profesionales, no para contribuir al incremento de las ganancias empresariales, sino para contribuir al desarrollo del país. Así afirma que: "La construcción económica exige técnicos: esa es la gran función de la universidad y esa la gran responsabilidad de esa minoría privilegiada que es el universitario: hacer 'política económica' científicamente cuando egresa de la universidad. Y el Estado tiene necesidad de emplear estos pensadores técnicos, porque estos planes de desarrollo no tienen por finalidad el impedir el posible advenimiento de un comunismo, sino el corregir una situación social y económica que es mala".

\section{Una persona imprescindible}

Sin duda alguna, muchos de nosotros recordamos al Padre Ibis 
como una persona cariñosa, amable y bromista. Y eso es cierto, pero no es todo lo que el padre era, pues encontramos en él una persona de carácter fuerte, y así lo describe él mismo en la carta de despedida del Decanato de Ciencias Económicas y Sociales que escribió en la Revista Ceteris Paribus"22: "Una de las tareas que también lleva su tiempo es la preparación de los horarios y la atención de la matrícula, donde los imprevistos de secciones superdemandazas y de las que se quedan enanas requiere la colocación de los famosos letreros: 'pase del aula A al aula Z'. Quizás han sido los días en que el 'Decano estaba más nervioso y cuasi intratable' y los alumnos más pacientes corriendo de aula en aula".

"La junta de directores creyó conveniente descargarme un poco de estas actividades administrativas, en que me han conocido largo tiempo, para que me dedique más a las clases y a emborronar algunas páginas con comentarios para nuestras revistas" ${ }^{23}$. En sus múltiples artículos podemos encontrar una enorme variedad de reflexiones que nos acercan al lado humano de la economía... es curioso que en su currículo vital únicamente menciona tener "bastantes artículos sobre temas económicos en el Boletín de Ciencias Económicas y Sociales, Realidad Económica y Social, Realidad, ECA..." 24 . En realidad no estoy segura de que tuviera una idea real de la cantidad de artículos que había publicado en diversas revistas y medios (más de 400), ni de la can- tidad de páginas que había escrito, que en conjunto sumaban miles.

Su primer artículo publicado lo encontramos en $1969^{25}$, con el título "La planificación del desarrollo social y económico". Sin embargo, es a partir de la segunda mitad de los años 70 que da inicio a una tradición de publicaciones en la Revista ECA y en el Boletín de Ciencias Económicas y Sociales. Desde entonces, no es difícil encontrar diversas publicaciones de su autoría, en las que analizaba relevantes temas acerca de problemas económicos mundiales y de El Salvador, sistemas económicos, crisis económicas, globalización, neoliberalismo, comentarios acerca de mensajes del Papa, comercio internacional, terrorismo, conferencias, cumbres y foros internacionales.

Sobre sus artículos resaltan varias características: una de ellas es el ingenio con que el Padre los titulaba, por ejemplo al referirse al "Secuestro en la renta nacional" (Boletín de CC. EE. y SS., 1978); "La unión hace la fuerza... La 'teoría de la pendencia'" (Boletín de CC. EE. y SS., 1979); "Inflación monetaria y deflación cívica" (Boletín de CC. EE. y SS., 1979); "Polonia se declara en huelga; y Rusia ¿qué?" (Boletín de CC. EE. y SS., 1980); “¿Hacia dónde va el Este? y ¿hacia dónde va el Oeste?" (Realidad, 1990); "La ley de privatización bancaria: ¿de la privatización a la privatización?" (Realidad, 1990); "El neoliberalismo no es un dogma de fe" (Realidad, 1992); "El reloj de ARENA marca 
cuatro años" (Realidad, 1993); "¿Socialismo en hibernación?" (ECA, 1996); "¿Es ético canonizar la globalización?" (ECA, 1997); "La economía imposible" (Realidad, 1997); "La evangelización del dinero" (Semanario Orientación, 1997); "El buen pastor da su vida. ¿Y qué dan las ovejas?" (Carta a las Iglesias, 1998); "La crisis económica internacional en El Salvador. Llueve sobre mojado" (Carta a las Iglesias, 1998); "Sí a la vida, no a la deuda" (Semanario Orientación, 1999); "¿Vamos a mejor o vamos a Dios sabe dónde?" (Semanario Orientación, 1999); "Teoría general del subempleo, el desinterés y la moneda" (Realidad, 2000); "Y después vino 'la dolarización'" (ECA, 2000); “¿De igual a peor?" (Semanario Orientación, 2000); "Reinventar el Estado y gobernar la globalización" (Realidad, 2001); "Del terrorismo, líbranos Señor" (Semanario Orientación, 2001); "Los manifestantes son dos" (Carta a las Iglesias, 2001); "Nuestra casa está ardiendo" (Semanario Orientación, 2002); "11 de septiembre, 'Economía del Terror' y Cumbre de Qatar" (Realidad, 2002); "La inseguridad: el regulador de la economía mundial" (Realidad, 2002); "La globalización anda en pena" (editorial Realidad, 2002); "Un mercado sin mercado" (Semanario Orientación, 2003); "La OMC de Cancún y el 'zar' Zoellick" (Carta a las Iglesias, 2003); "La oración del Salario Mínimo: 'Danos hoy el pan nuestro de cada día'" (Carta a las Iglesias, 2003); "Las amenazas duras y las amenazas blandas" (Semanario
Orientación, 2004); “El eje del mal: la pobreza, el SIDA y la guerra" (Semanario Orientación, 2004); "Un ALCA 'a dos velocidades'" (ECA, 2004); "La 'guerra sin fin', un error" (ECA, 2004); "La sombra de Bombay se proyecta en Davos 2004" (Realidad, 2004); "¿Qué es el bien y quién es el mal?" (Semanario Orientación, 2005); "Los 45 cofrades de la Casa Blanca" (Carta a las Iglesias, 2005); "Bush II y la crisis del multilateralismo" (Realidad, 2005); "Los terroristas están ganando la guerra" (Realidad, 2006); entre otros temas.

De sus artículos, resalta además lo acertado de sus comentarios; por ejemplo, cuando afirma que: "El trabajo de los buenos estadígrafos es importante porque nos suele dar porcentajes reales, acompañados de explicaciones razonadas, que contradicen el discurso de tantos jefes de Estado especialistas en estadística imaginaria [y que] la ausencia de Estado no garantiza la libre competencia, ni el buen funcionamiento de los mercados. A los países del Tercer Mundo, es decir, a sus gobiernos, se les ha engañado con la imagen distorsionada del conceptoparadigma de mercado. Dada su rápida transformación cuantitativa y cualitativa, los países en desarrollo descubren, a costa propia, que el mercado no es un buen paradigma $y$, por tanto, no es un 'modelo'" 26. De manera similar, afirma que "a partir del 11 de septiembre de 2001, la amenaza de este terrorismo, sobre todo a Estados Unidos, desbanca la atención que las nacio- 
nes más poderosas debieran prestar a los objetivos del milenio. (...) El foro económico de Davos, celebrado en 2002, tiene lugar en Nueva York, 'la ciudad mártir' y Bush relanza la guerra contra el terrorismo; [sin embargo] la amenaza no era militar, sino económica y con olor a petróleo. En pleno declive de la economía norteamericana, el 6 de noviembre de 2000, el gobierno de Irak, segundo o tercer productor de petróleo, transfiere sus multimillonarios activos de la zona dólar a la zona euro" ${ }^{\prime 27}$.

Por otra parte, resalta el dominio que tenía acerca de los pronunciamientos de otros autores y/o personajes importantes de la vida nacional e internacional. Por ejemplo, cuando comenta que "en febrero de 2000 se reúne en Bangkok, Tailandia, la décima conferencia de las Naciones Unidas sobre Comercio y Desarrollo. El presidente saliente del FMI, Michel Camdessus, fue recibido con un pastelazo de crema tailandesa en la cara. Son gajes del oficio, dijo, y pronunció su discurso de despedida. He aquí un párrafo: “¿Por qué tanta ansiedad y por qué tantos rechazan la globalización como un símbolo de las nuevas tendencias económicas? La respuesta es que aún no se ha demostrado que la globalización se preocupe lo suficiente por el problema más grave de nuestra era, la pobreza, o que sea capaz de resolverlo. La brecha creciente entre los ricos y lo pobres y el abismo que separa a los más ricos de los más pobres son moralmente inadmisibles, económicamente ineficientes $y$, desde un punto de vista social, potencialmente explosivos. Hoy es evidente que no basta aumentar el tamaño de la torta; la forma en que se reparte es esencial" ${ }^{\prime 28}$.

El Padre era además alguien que se enojaba mucho ante la injustita del mundo y del sistema. Por ejemplo, en su artículo "La teoría de la oferta ¡Ya se ensayó en los países pobres!"29, afirma que "la teoría de la oferta nos entra por 'efecto goteo' y el 'sector productivo' se siente una vez más llamado a ser la columna vertebral de la economía. Los apoyos estatales, las desgravaciones fiscales, el juego de la libre iniciativa se espera que generen los 'incentivos' que mueven la actividad productiva de los empresarios, aumentando el empleo con menor tasa de inflación. Nos quedamos a la expectativa de lo que en el pasado siglo se tomó más de cien años para hacer sentir sus efectos. $Y$ es que ahora los economistas se han quedado inermes 'sin teoría económica', con el peligro de olvidar lo que ya estaba inventando. Con los residuos de teoría y de historia que aún nos quedan podemos decir que la 'teoría de la oferta' no ha funcionado en las economías subdesarrolladas, y funcionará menos aún en aquellas que enfrentan conflictos civiles, cuyo origen hay que buscarlo en la propia teoría de la oferta".

Su indignación ante la injusticia la demostraba también cuando 
hablaba acerca de la Organización Mundial del Comercio (OMC), refiriéndose a ella como la Babilonia del nuevo milenio, o cuando se refería al Fondo Monetario Internacional, el Banco Mundial y la OMC como la Trinidad Pagana; o cuando compartía sus ideas sobre la cuadriga del colonialismo económico: la desregulación, la liberalización, la privatización y la promoción del comercio exterior.

Personas como el Padre Ibis son imprescindibles porque nuestro mundo necesita hombres y mujeres que, como él, se entregan a la búsqueda de la verdad y posean un profundo amor por compartirla humildemente; baste consultar su artículo "Sin verdad no hay paz ni justicia mundial" (ECA, enero 2006).

Quiero finalizar este pequeño comentario con las palabras de cierre que el Padre nos trasladó en su artículo "Los treinta años de la

Notas

1 Ibisate, P. Fco. Javier. "Carta a Ceteris Paribus" en Revista Ceteris Paribus. Año II, número 2; Junio de 2001, p. 3.

2 Clase de Introducción a la Economía I impartida por el Padre Ibisate, haciendo referencia a Joseph Schumpeter. Apuntes de clases.

3 Clase de Introducción a la Economía I, impartida por el Padre Ibisate. Apuntes de clases.

4 Ídem.
UCA": "En razón de ser uno de los antiguos inventarios de la UCA, quiero agradecer los valiosos refuerzos, jesuíticos y no jesuíticos, que se han sumado a esta tarea universitaria después y a raíz del asesinato de nuestros compañeros y empleadas. Les ha atraído esta universidad, no por sus bonitos jardines y su paisaje (lo cual es muy cierto), sino porque se respira un aire académico y teológico distinto, que les hace sentirse más realizados que en sus países de origen. Esto mismo nos ha pasado a otros muchos. Lo importante es que su venida y su colaboración nos siguen reconfortando. El resto de la historia ya no son memorias, sino un presente que cumple treinta años. Ojalá que estas breves memorias y el sexto aniversario de nuestros mártires nos ayuden a reavivar nuestra historia. Para algo tiene que servir tener memoria." (Las cursivas son mías).

Con mucho cariño, Padre lbis.

5 Clase de Introducción a la Economía II, impartida por el Padre Ibisate. Apuntes de clases.

6 Ídem.

7 Ídem.

8 Ídem.

$9 \quad$ Ibisate, P. Francisco Javier. "¿Es capitalista el capitalismo salvadoreño?”, en Revista ECA; julio-agosto 1979; p. 536.

10 Clase de Sistemas Económicos Comparados, impartida por el Padre Ibisate. Apuntes de clases. 


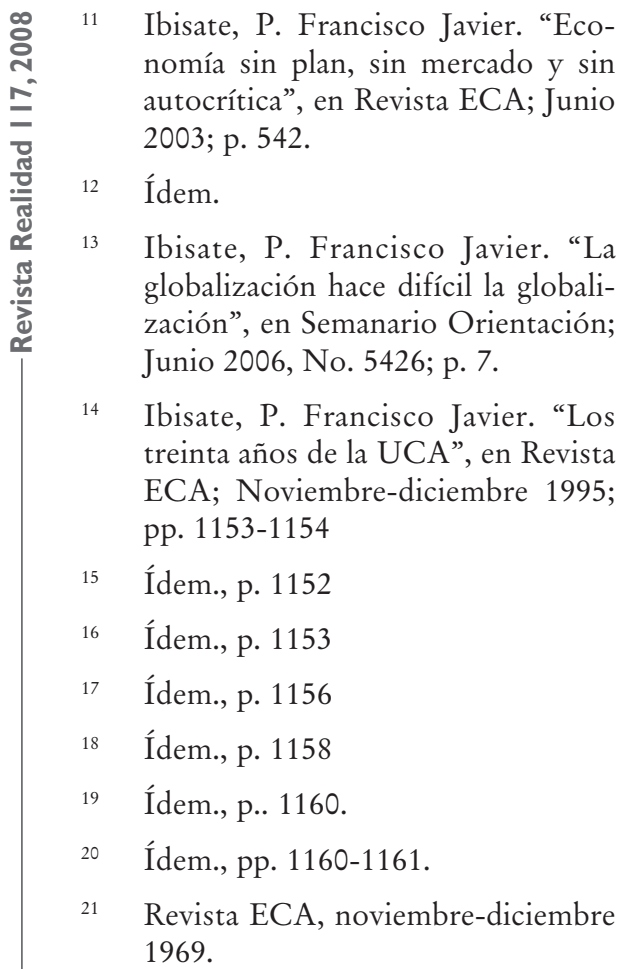

23

24

25 la oferta iya se ensayó en los países pobres!", en Boletín de Ciencias Económicas y Sociales; Septiembreoctubre 1981; p. 269. 